\title{
Rockfall mitigation measures and design scenarios at the base of highwalls
}

\author{
C Lambert Golder Associates (NZ) Ltd, New Zealand \\ F Ferrari The University of Newcastle, Australia \\ K Thoeni The University of Newcastle, Australia \\ A Giacomini The University of Newcastle, Australia
}

\begin{abstract}
This paper proposes to discuss the efficiency of typical rockfall mitigation measures implemented in open cut environments and aims at providing geotechnical engineers and mining engineers with some guidance for preliminary rockfall hazard assessment and management strategies. Firstly, a semi-quantitative approach is presented. An extensive sensitivity analysis of rockfall trajectories to highwall geometry was performed. Relationships were derived to estimate the expected rockfall energies and first impact location at the base of the highwall. An example of how these relationships can be used for the preliminary design of a protective berm is presented. Secondly, the efficiency of unsecured drapery systems is investigated using a three-dimensional discrete element model. A wide range of rockfall scenarios were simulated to quantify the efficiency of draperies to reduce impact energies and constrain impact location close to the highwall. Implications for the design of underground entry portals and canopies are discussed where design requirements derived from the semi-quantitative approach are compared with examples of design scenarios currently used by practitioners.
\end{abstract}

\section{Introduction}

Rockfalls pose serious threats to workers, machineries and structures in open pit mines which need to be properly managed to ensure a safe working environment. A common mitigation approach consists in multiple lines of defence that include installation of rock bolts, draperies, and/or protective berms in rockfall prone areas, specification of stand-off distances for machinery and personnel, and construction of concrete culverts where underground entries are required.

Such strategies have been implemented in numerous mine sites to successfully mitigate rockfall; they, however, do not completely eliminate the hazard. Drapery systems, for example, may cover the extent of the initiation zone of rockfall prone areas but blocks can still detach and fall in between the mesh and the rock face. Therefore, an accurate assessment of the residual hazard, once such protective systems are in place, is essential for a safe operation of a mine site. Currently, no guidance is available to assess the residual hazard and the efficiency of some of these systems has only been recently investigated (Volkwein 2005; Muhunthan \& Radhakrishnan 2007; Trad et al. 2011; Giacomini et al. 2012a).

This paper aims at providing general guidance for rockfall management in a mining environment. Extensive rockfall trajectory simulations are used to derive qualitative relationships that can be used for preliminary design purposes. Efficiency of protective berms and of unsecured draperies is more specifically discussed, along with recommendations for design scenarios to be used in the design of concrete portals. 


\section{Rockfall trajectories in open cuts}

\subsection{Sensitivity analysis}

The method is based on a two-dimensional (2D) sensitivity analysis, conducted by means of kinematic simulations based on probabilistic modelling of rockfall trajectories with RocFall ${ }^{\circledR}$ v4. The sensitivity analysis was carried out for a large range of input parameters and considering all possible combinations, in order to take into account the uncertainty associated with their estimated values.

An idealised rock wall geometry was adopted where the wall is represented by a single straight line. Parameters considered for the sensitivity analysis include slope angle, height, and roughness, as well as normal and tangential coefficients of restitution (Table 1). Statistical analyses were conducted to derive simple empirical laws to estimate the range of both the expected kinetic energy and potential distance of the first impact at the base of the rock cliff. The 90th percentile of translational kinetic energies and the 95th percentile of distances were considered as representative for rockfall hazard assessment and mitigation purposes (Abbruzzese et al. 2009). This first impact will be referred to herein as bottom impact. Full details of the sensitivity analysis can be found in Ferrari et al. (2016).

Table 1 Parameters and input values used in the sensitivity analysis

\begin{tabular}{cccc}
\hline Property & Symbol & Unit & Input values \\
\hline Slope height & $h$ & $m$ & $5,10,15,20,25,30,35,40,45,50,55,60$, \\
& & & $65,70,75,80,85,90,95,100$ \\
\hline Slope angle & $\alpha$ & - & $50,55,60,65,70,75,80,85$ \\
\hline Standard deviation of roughness & $\sigma_{r}$ & - & $0,1,2,3,5,7,10,13,15,20$ \\
\hline Normal restitution coefficient & $k_{n}$ & - & $0.4,0.5,0.6,0.7,0.8,0.9,1.0$ \\
\hline Tangential restitution coefficient & $k_{t}$ & - & $0.3,0.4,0.5,0.6,0.7,0.8,0.9$ \\
\hline
\end{tabular}

\subsection{Bottom impact energy}

The 90th percentile of translational kinetic energy, $E_{90}$, was normalised by the potential energy of the block available at the source, $E_{p o t}$ (i.e. the maximum energy available at the start of the fall), (Figure 1). A bottom impact energy ratio can be expressed as:

$$
\mathrm{R}_{\mathrm{E}}=\frac{\mathrm{E}_{90}}{\mathrm{E}_{\mathrm{pot}}}=\frac{\mathrm{E}_{90}}{\mathrm{~m} \times \mathrm{g} \times \mathrm{h}}
$$

where: $m$ is the mass of the block, $g$ is the acceleration of gravity and $h$ is the vertical drop from the rockfall source to the base of the highwall.

This ratio characterises the expected translational kinetic energy at the base of the highwall and the energy dissipated during the fall $\left(1-R_{\mathrm{E}}\right)$. Results show that the bottom impact energy ratio is primarily controlled by the slope angle $\alpha$ and, to a lesser extent, by the slope roughness $\sigma_{r}$. In particular, shallower slopes dissipate more energy (lower energy ratio) due to an increasing number of impacts on the slope along the fall. Interestingly, the coefficients of restitution, $k_{n}$ and $k_{t}$, play a secondary role (Figure 1 ). 


$$
h=50 \mathrm{~m}
$$
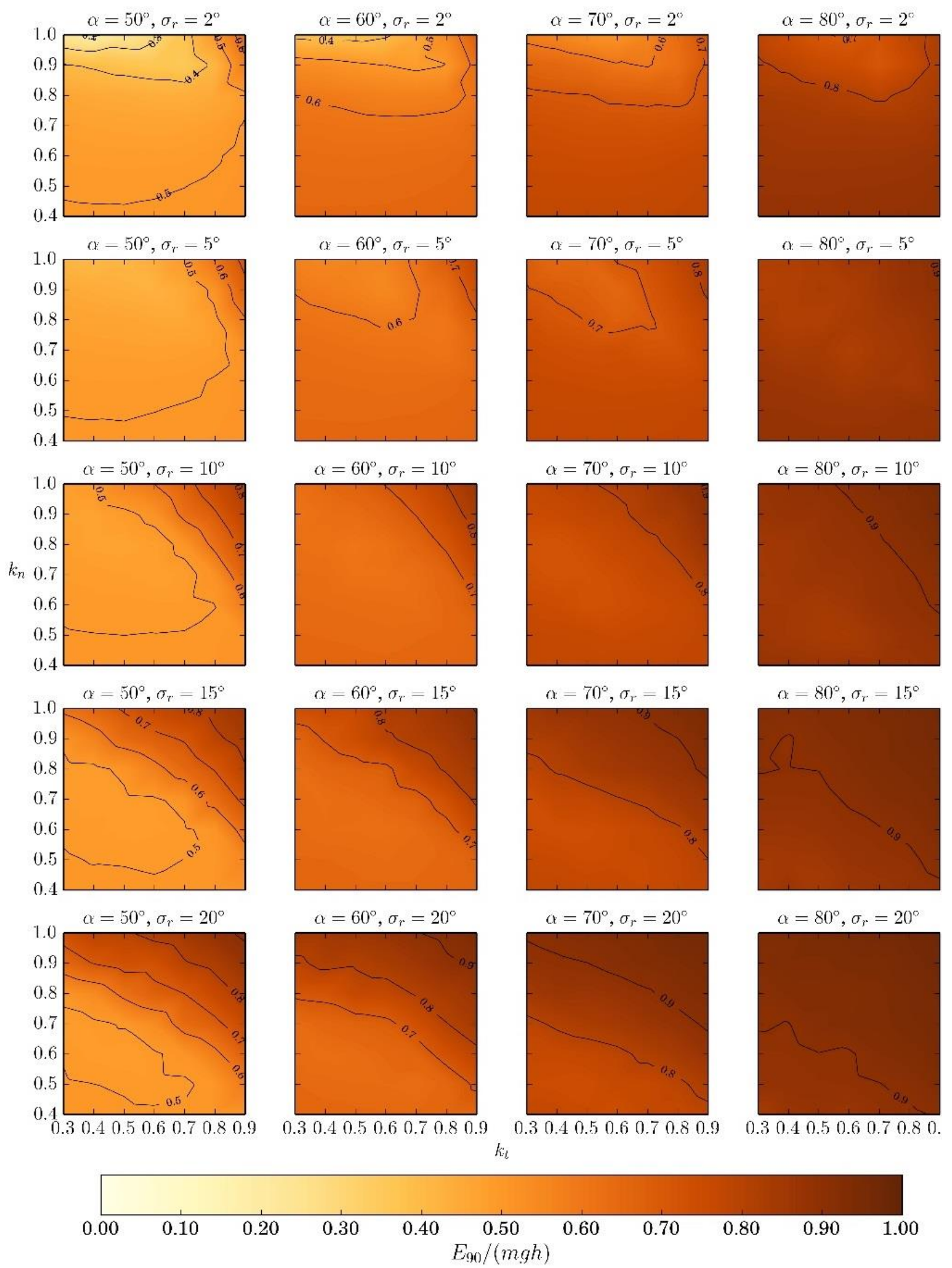

Figure 1 Bottom impact energy ratio $R_{E}$ for $\mathrm{h}=50 \mathrm{~m}$. Each column represents a different slope angle, $\alpha$, and each row a different roughness standard deviation, $\sigma_{r}$. In each plot, the ratio of the 90th percentile of kinetic energy and the potential energy is displayed, as a function of all the combinations of $k_{n}$ and $k_{t}$ 
Considering the secondary influence of restitution coefficients on the kinetic energy and the uncertainty associated with their estimates, all bottom impact energies can be grouped according to slope morphology (i.e. slope angle and roughness) from which an average $\left(E_{90, \text { mean }}\right)$ and a maximum $\left(E_{90, \max }\right)$ value can be derived. Ferrari et al. (2016) observed a linear relationship between $E_{90, \text { mean }}$ and slope height (or vertical drop) $h$ and derived, for each slope morphology, energy regression coefficients (ERC) $E R C_{\text {mean }}$ and $E R C_{\max } w_{h e r e b y}$ $E_{90, \text { mean }}=E R C_{\text {mean }} \times \mathrm{m} \times \mathrm{h}$ and $E_{90, \text { max }}=E R C_{\max } \times \mathrm{m} \times \mathrm{h}$. The values of $E R C_{\text {mean }}$ and $E R C_{\text {max }}$ for specific values of $\alpha$ and $\sigma_{r}$ are summarised in Figure 2.
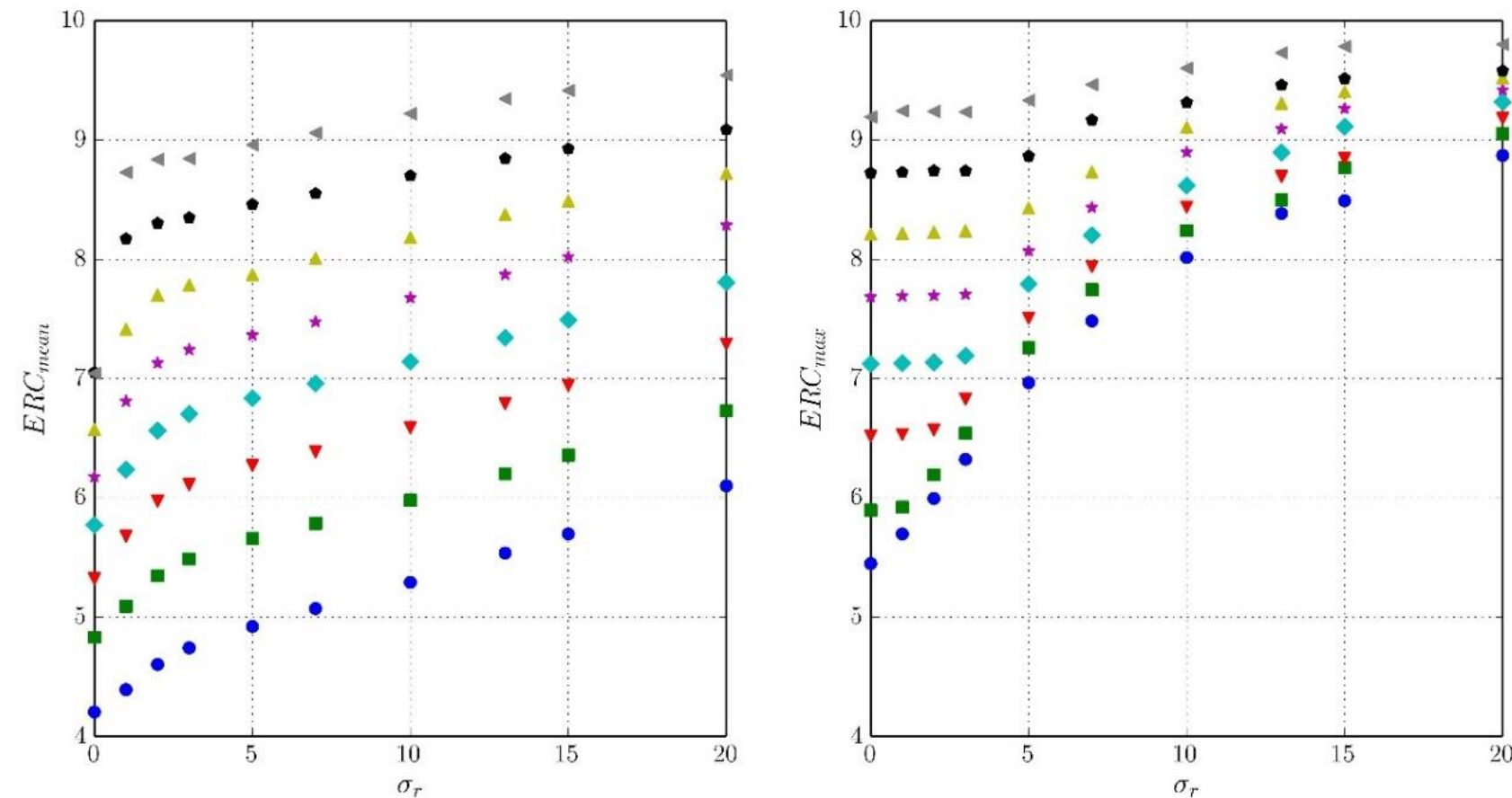

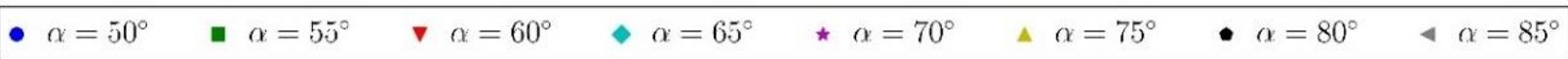

Figure $2 E R C_{\text {mean }}$ (left) and $E R C_{\max }$ (right) as a function of $\sigma_{r}$ and $\alpha$

$E_{90, \max }$ considers the worst expected condition (i.e. the highest $E_{90}$ ) to be used for the design of mitigation measures, and $E_{90, \text { mean }}$ corresponds to the average expected $E_{90}$. Therefore, $E R C_{\max }$ and $E R C_{\text {mean }}$ should be used to derive an expected range of kinetic energies to be used for design purposes.

\subsection{Bottom impact location}

Another important aspect of rockfall mitigation in a mining environment is the impact location at the base of the highwall. The bottom impact location is defined as the horizontal distance between the first impact at the bottom of the mine and the base of the highwall. The results of the 95th percentile of the horizontal distance from the wall of the first impact $d_{95}$ were derived and normalised by the slope height (or vertical drop height) $h$ (Figure 3). Results show that the ratio $R_{d}=d_{95} / h$ is mainly controlled by slope roughness, followed by slope angle, with restitution coefficients $k_{n}$ and $k_{t}$ again playing a secondary role. 


$$
h=50 \mathrm{~m}
$$
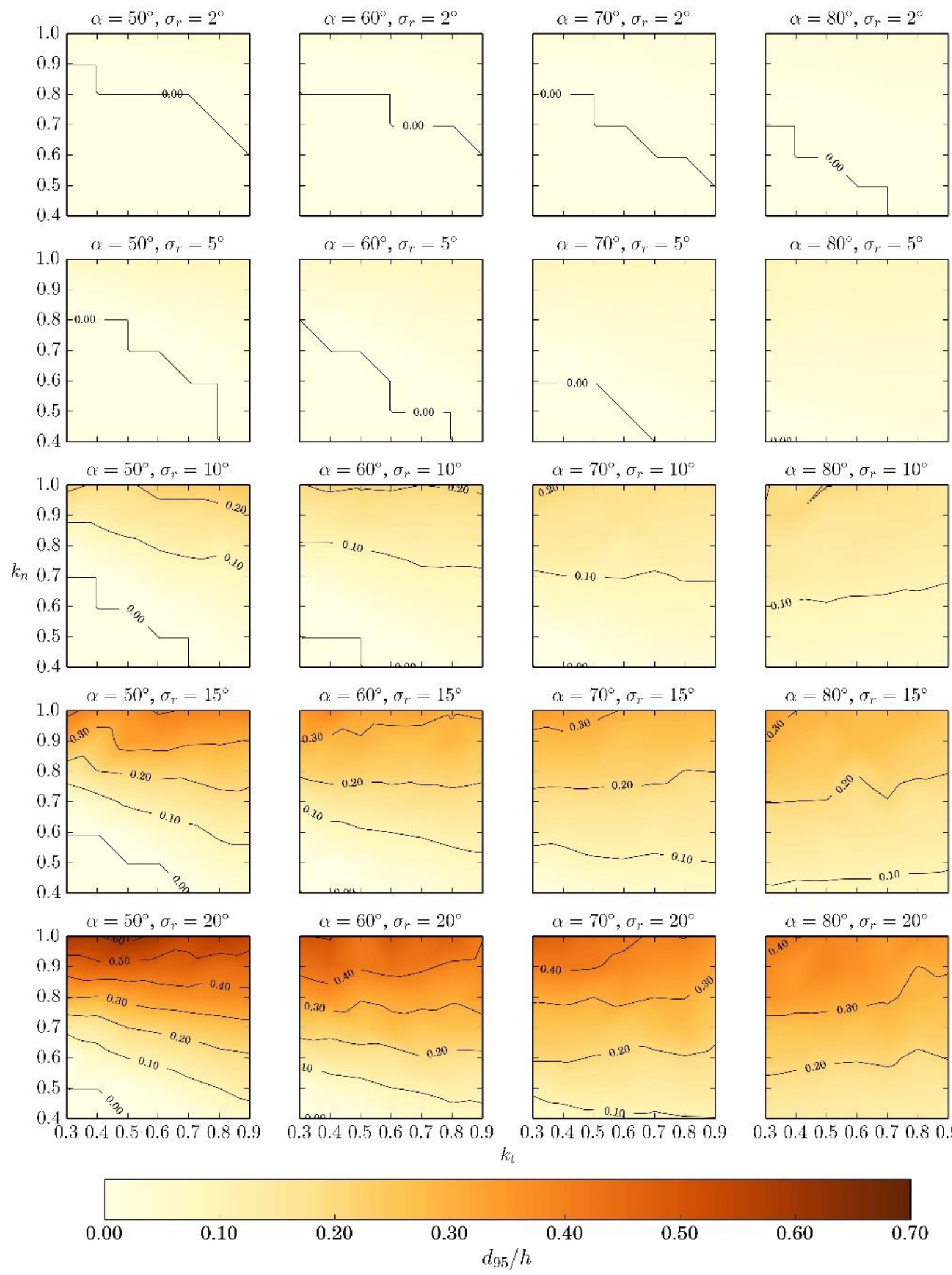

Figure 3 Bottom impact location for $\mathrm{h}=50 \mathrm{~m}$. Each column is associated to a different slope angle $\alpha$ and each row to a different slope roughness $\sigma_{r}$. Each plot depicts the ratio of the 95th percentile of impact location and $h$, for all the combinations of $k_{n}$ and $k_{t}$ 
The influence of surface roughness is clear whereby $d_{95}$ increases with increasing $\underline{\sigma}_{r}$ due to the presence of irregularities (also called launching features) along the slope profile. For very smooth slopes (i.e. $\underline{\sigma}_{r}<3^{\circ}$ ), where rolling prevails, the first impact location of the block is very close to the slope.

The effect of slope angle on $d_{95}$ is less significant and not so simple to define. As with the kinetic energy, $d_{95}$ values can be grouped by slope morphology (i.e. similar slope angle and slope roughness). Ferrari et al. observed a linear trend between the bottom impact location $d_{95}$ and the slope height (or vertical drop height) and introduced a range of impact locations for design purposes defined by $d_{95, \text { mean }}$ and $d_{95, \max }$ (Ferrari et al. 2016). While $d_{95, \text { mean }}$ generally increases with slope angle, $d_{95, \text { max }}$ tends to increase for low roughness values only. Scattering of block impacts at the base of a slope tends to increase as the slope angle decreases.

For a given slope morphology (i.e. same slope angle and slope roughness), $d_{95, \text { mean }}$ and $d_{95, \text { max }}$ can be derived directly from $\mathrm{h}$ through two linear relationships. Two linear distance regression coefficients (DRC) for $d_{95, \text { mean }}$ $\left(d_{95, \text { mean }}=D R C_{\text {mean }}{ }^{*} h\right)$ and $d_{95, \text { max }}\left(d_{95, \text { max }}=D R C_{\text {max }}{ }^{*} h\right)$ were calculated to estimate the expected range of impact location (Figure 4).

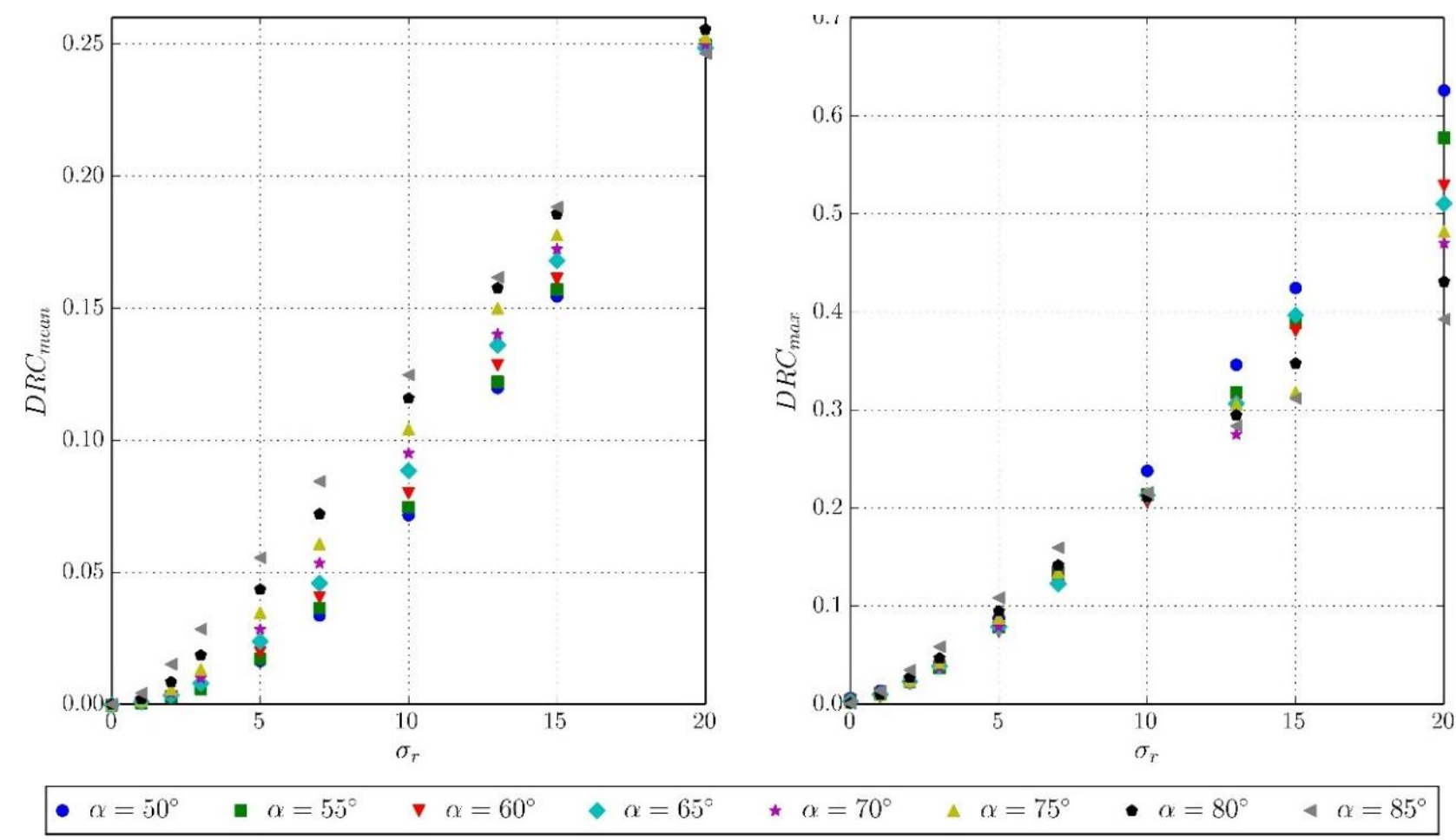

Figure $4 \mathrm{DRC} C_{\text {meam }}$ (left) and $\mathrm{DRC} C_{\max }$ (right) as a function of $\sigma_{\mathrm{r}}$ and $\alpha$

\subsection{Slope roughness and irregularity class}

While slope angle can be easily obtained with a reasonable level of confidence through compass measurements, photogrammetric models and/or in situ surveys, estimating slope roughness $\sigma_{r}$ for rockfall trajectory simulations is generally more difficult and subjective.

To overcome this problem, irregularity classes as introduced in the ROFRAQ methodology (Alejano et al. 2008) were used (Figure 5). The ROFRAQ methodology was developed for assessing the rockfall risk in ornamental stone quarries and defines five face irregularity classes. Each slope is attributed a face irregularity class by comparing the observed rock wall profile with five reference profiles. 

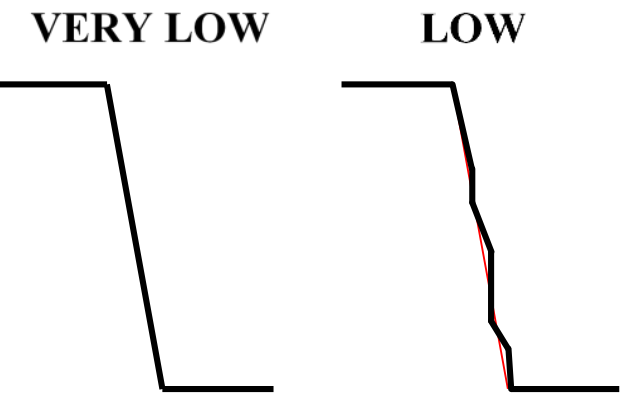

AVERAGE

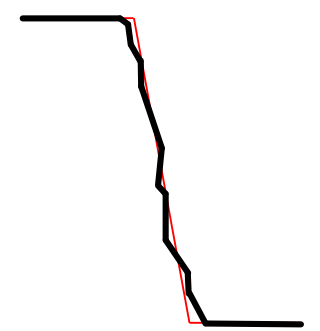

HIGH

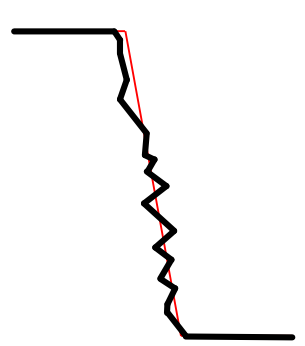

VERY HIGH

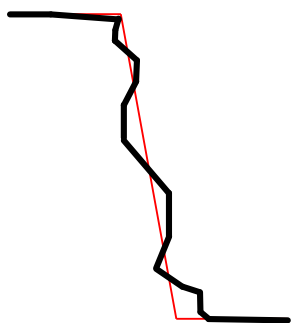

Figure 5 Face irregularity classes (modified after Alejano et al. 2008)

Ferrari et al. (2016) conducted a survey of 27 engineers/engineering geologists to correlate each face irregularity class to a specific slope roughness $\sigma_{r}$ calculated from high definition digital photogrammetric profiles. $\sigma_{r}$ values representative of each face irregularity class were proposed: $7^{\circ}$ for very low, $10^{\circ}$ for low, $13^{\circ}$ for average, $15^{\circ}$ for high, and $20^{\circ}$ for very high. It should be noted that these values correspond to the roughness of a slope profile when compared to an idealised straight slope profile and caution should be taken when used with profiles that introduce some degree of irregularity.

\section{Efficiency of protective berms}

This section focuses on protective berms as a rockfall mitigation system and presents a methodology, based on the semi-empirical relationships derived in Section 2, for their preliminary design (location and height).

The methodology presented in Section 2 was applied to investigate the efficiency of a protective berm constructed at the base of a particular highwall. The highwall consists mainly of successive layers of sandstone and siltstone of varying thicknesses. In the area of interest, the highwall has an average height of approximately $40 \mathrm{~m}$ and is dipping at $70^{\circ}$ (Figure 6). A design block size of $25 \mathrm{~kg}\left(10^{-2} \mathrm{~m}^{3}\right)$, corresponding to the 95th percentile of the in situ block size distribution, was used in this study.

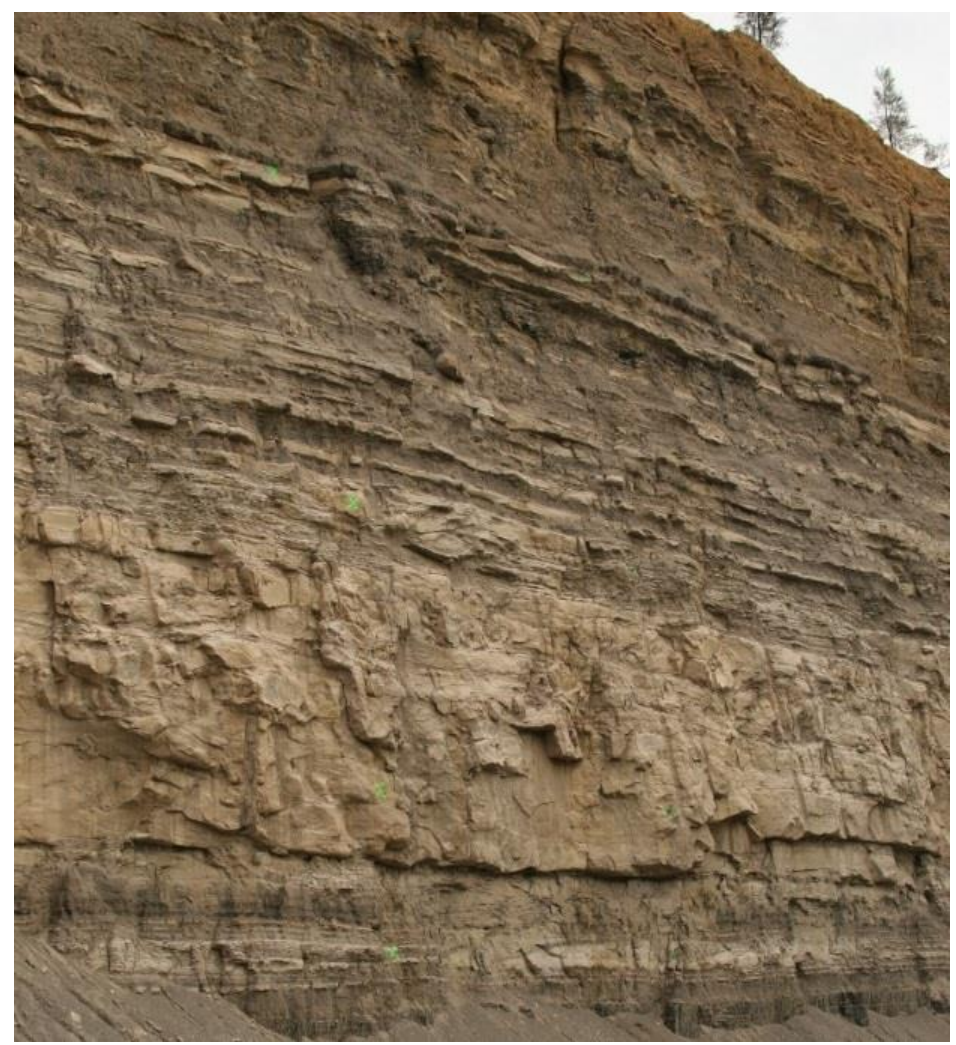

Figure 6 View of the highwall 
The highwall was attributed a surface irregularity class of average to high, therefore corresponding to slope roughness values of 13 to $15^{\circ}$. Based on Figure 2, regression coefficients $E R C_{\text {mean }}$ and $E R C_{\text {max }}$ of 8.0 and 9.3 can be considered as representative for the highwall. Therefore, the bottom impact kinetic energy is expected to range between 8 and $9.3 \mathrm{~kJ}$ (i.e. $8.0 \times 25 \times 40$ to $9.3 \times 25 \times 40$ ).

Similarly, based on Figure 4, regression coefficients $D R C_{\text {mean }}$ and $D R C_{\max }$ of 0.17 and 0.35 can be used for the highwall (i.e. $\sigma_{r}=15^{\circ}$ and $\alpha=70^{\circ}$ ). The design impact location is expected to range between 7 and $14 \mathrm{~m}$ (i.e. $0.17 \times 40$ and $0.35 \times 40$ ) and, therefore, the crest of a protective berm should be situated within that range. A protective berm with a crest situated closer than $7 \mathrm{~m}$ from the highwall will not offer sufficient rockfall hazard mitigation as an excessive number of blocks can be expected to bypass the bench by impacting behind it. Conversely, a crest situated at $14 \mathrm{~m}$ is expected to provide sufficient mitigation even for the most adverse slope conditions. Situating the berm within the recommended range requires a risk based approach (where the consequences are included in the decision) or more specific trajectory simulations.

Impact kinetic energy can be used to estimate the maximum rebound height and therefore the minimum berm height to prevent any block rebounding over the berm. Using normal and tangential restitution coefficients of 0.2 and 0.7 respectively due to the presence of large amounts of debris at the base, a maximum rebound height of $1.5 \mathrm{~m}$ is obtained. It is therefore expected that a $1.5 \mathrm{~m}$ high berm located approximately $14 \mathrm{~m}$ from the highwall will reduce the likelihood of a rockfall affecting the area downslope of the berm to $5 \%$.

For validation purposes, rockfall trajectory simulations were performed on one section of the highwall (Figure 7). The RocFall ${ }^{\circledR}$ model of the highwall described in Lambert et al. (2012) was used. The 2D slope profile was obtained from high definition 3D digital images, such that no additional roughness is required for trajectory simulations and coefficients of restitution, normal and tangential, for each lithology were computed from 3D trajectories recorded during in situ rockfall experiments performed at the site (Giacomini et al. 2012b). The model was previously validated against the rockfall experiments demonstrating its ability to accurately describe the rockfall trajectories (from a statistical standpoint) and was previously used to derive a quantitative rockfall assessment at the base. Full details of the model, including calibration and validation, can be found in Lambert et al. (2012).
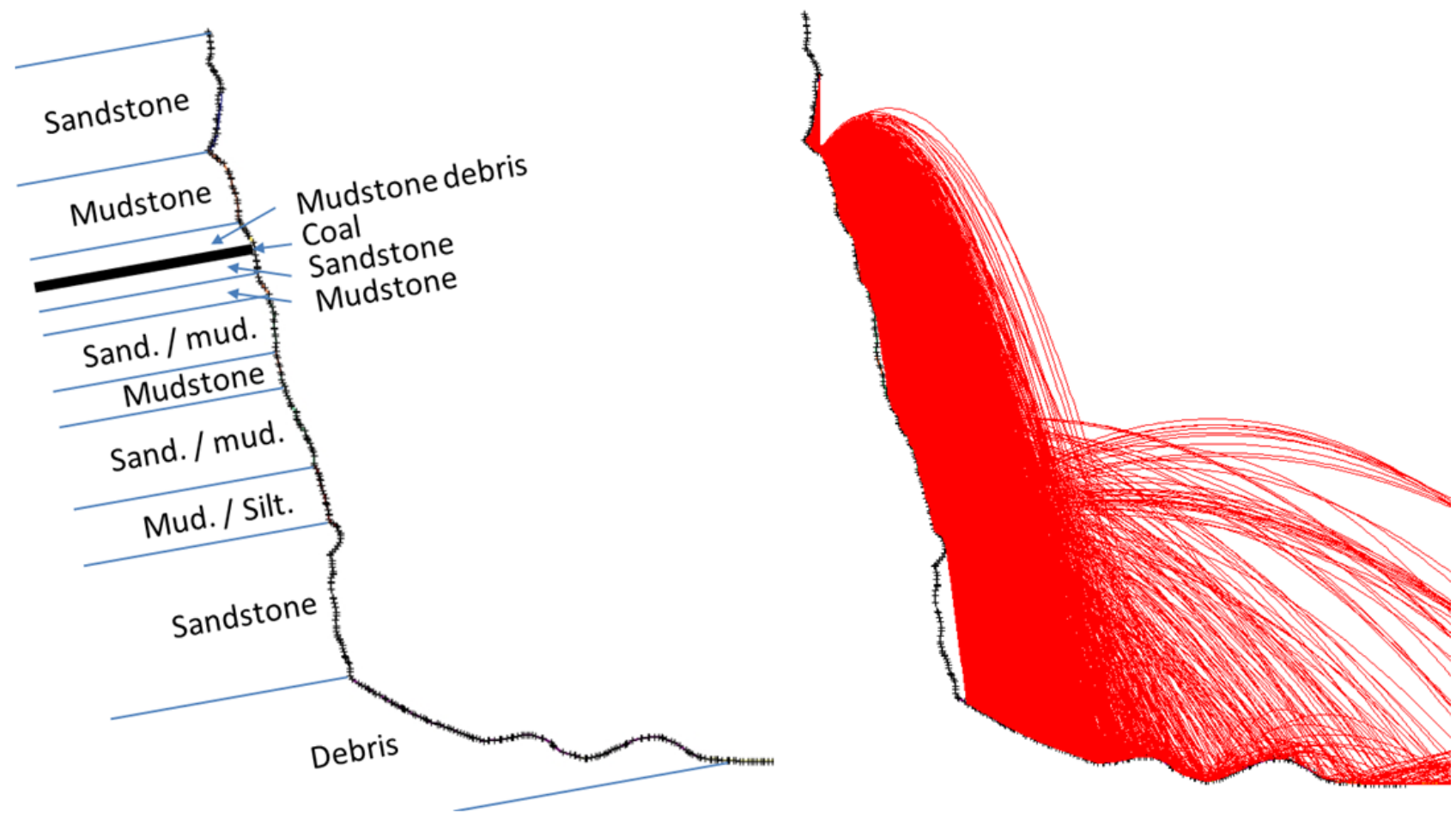

Figure 7 (left) topographical and simplified geological profile of the highwall; and, (right) resulting rockfall trajectories 
Statistical descriptions of rockfall trajectories were derived for that particular cross-section from 2,000 trajectories (Figure 8). Results show that the 95th percentile for the bottom impact location is located $14.1 \mathrm{~m}$ from the base of the highwall, confirming the recommended value obtained using the simplified methodology described in this paper. Similarly, the 90th percentile of bottom impact energy of $8.3 \mathrm{~kJ}$ falls within the recommended range of impact energies.
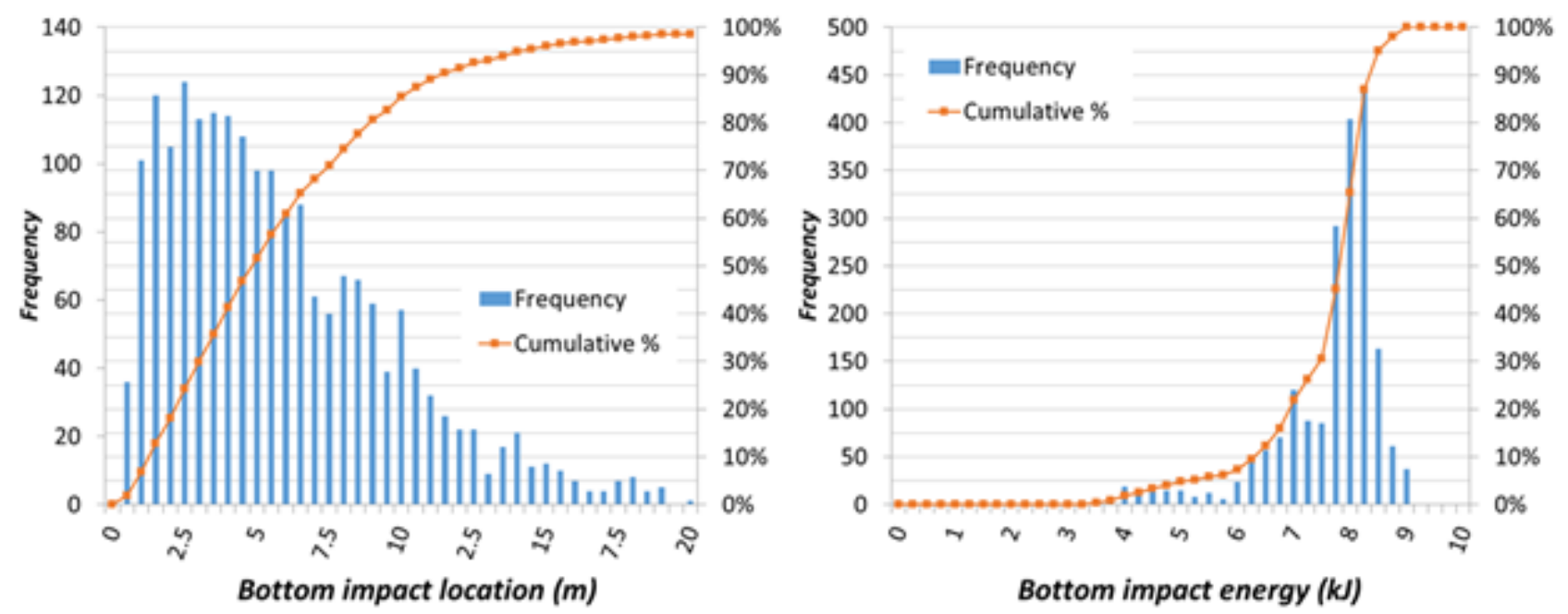

Figure 8 Based on 2,000 rockfall trajectories the: (left) statistical distribution of bottom impact location; and, (right) kinetic energy

At the base of the highwall, a $1.3 \mathrm{~m}$ high protective berm was initially constructed approximately $15 \mathrm{~m}$ from the highwall, i.e. similar to the recommended protective berm. Rockfall trajectories were analysed to assess the efficiency of such a berm as a hazard mitigation measure. Statistical distribution of end point locations show that $94 \%$ of the falling blocks were expected to be constrained within the catchment area defined by the berm (Figure 9), confirming the appropriateness of methodology for protective berm recommendations for preliminary design purposes.

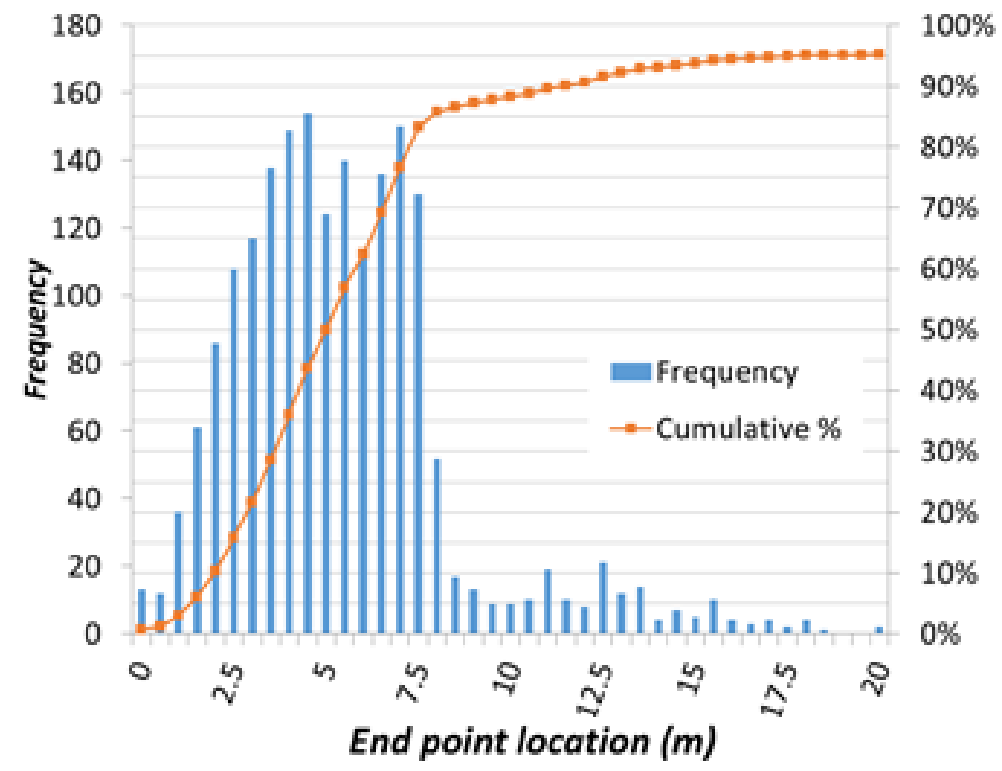

Figure 9 The statistical distribution of run-out distances with a protective berm 


\section{$4 \quad$ Efficiency of draperies}

Unsecured draperies are commonly used, alongside protective berms, for rockfall hazard mitigation. This section discusses their performance and presents a means of quantifying the residual hazard at the base of a highwall.

\subsection{Rockfall trajectory behind draperies}

Despite drapery systems having been used as a rockfall protective measures for many years, it is only recently that their design has been addressed in scientific literature. To date, the focus has been on experimental testing of single components (Muhunthan \& Radhakrishnan 2007) and on full-scale field testing (Bertolo et al. 2009; Giacomini et al. 2012b). Although several numerical models for restraining nets and net barriers have been presented in scientific literature (e.g. Volkwein et al. 2011), the modelling of draperies as a whole system has been rarely addressed.

For this study, a discrete element model, developed by the authors, was used to investigate the efficiency of draperies. The drapery is represented by spherical particles, which are located at the physical nodes of the double-twisted hexagonal mesh the drapery is built of (Figure 10). In order to model, the wire behaviour particles are linked remotely, which means interactions exist without direct contact (Thoeni et al. 2014). The rock slope is represented by triangular elements, whereas a block is modelled as a rigid assembly of spheres. The interaction between slope and block consists of interactions between fixed triangles and dynamic spheres. Energy dissipation during impact is considered via viscous damping and friction. Details of the model can be found in Thoeni et al. (2013). The benefit of the method is to explicitly account for blocks of arbitrary shape and size, for slope surface irregularities and for all the interactions involved during a rockfall event (i.e. block/slope, block/mesh and slope/mesh).
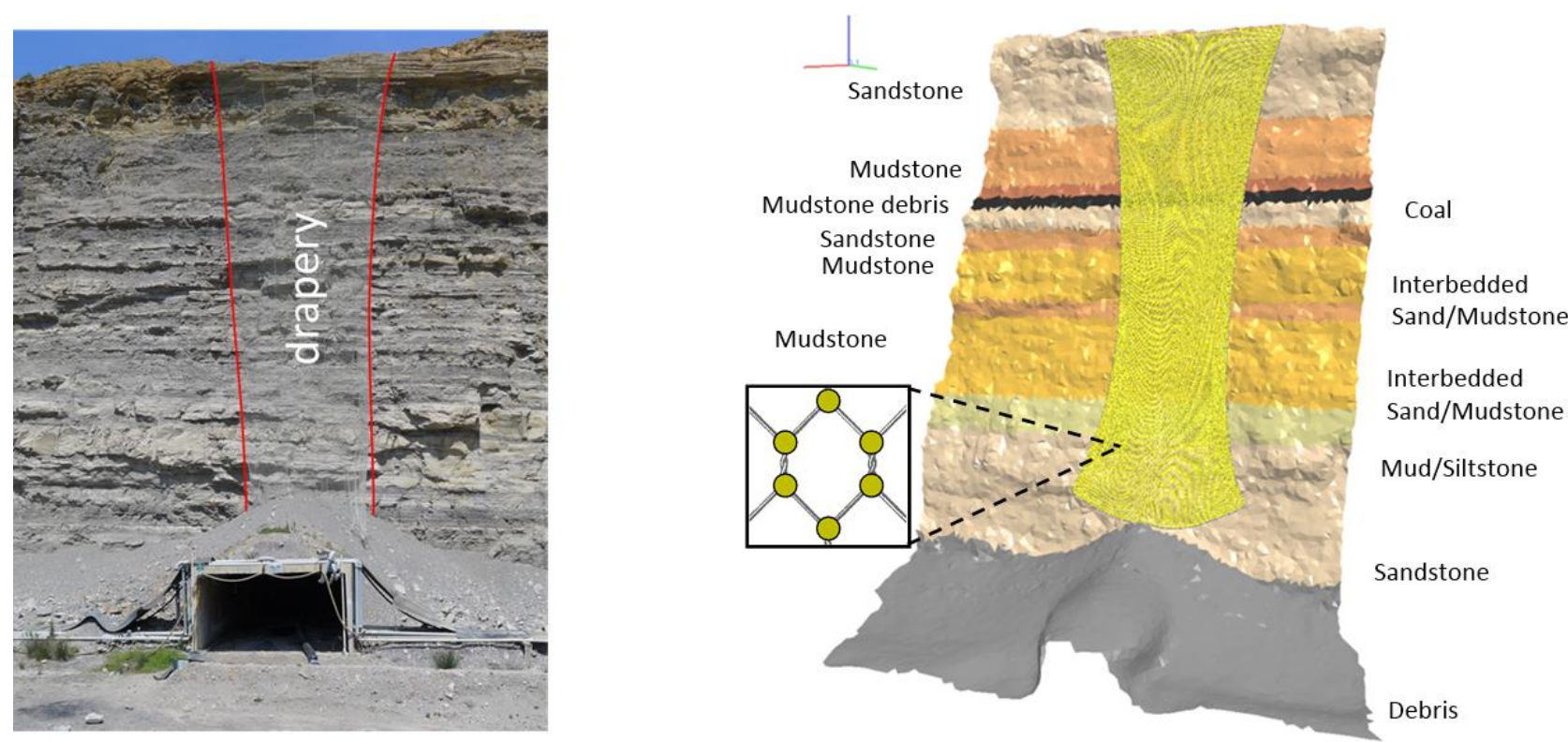

Figure 10 (left) Picture of a highwall with drapery and portal entry; and, (right) numerical representation of the same highwall (Thoeni et al. 2014)

\subsection{Performance of draperies}

While site specific modelling should be performed for a quantitative assessment of the residual hazard, such analysis can be time consuming and is not practical at an early stage of a project. In an attempt to derive preliminary design recommendations, a database of rockfall scenarios developed by Giacomini et al. (2012a) was analysed. 
Nine different blocks are considered as a combination of three different shapes (sphere, cube and elongated cube) and three characteristic dimensions $(0.2,0.4$ and $0.8 \mathrm{~m})$ resulting in the mass ranging from $10.1 \mathrm{~kg}$ (0.2 $\mathrm{m}$ sphere) to $2.5 \mathrm{t}$ ( $0.8 \mathrm{~m}$ elongated cube).

A standard geometry considered in the parameter study is based on the highwall section presented in Section 3. Some modifications to the slope morphology are introduced to investigate a range of irregularities. Figure 11 shows an example of a geometry modified with a ledge. Ledges at different heights with different depths are introduced to generate different slope scenarios. Three of each blocks are then released from three positions at the same elevation on the highwall. Block trajectories during the fall are recorded, from which kinetic energy, and bouncing distance from the highwall, are derived. The energy and the location of the bottom impact, after a $40 \mathrm{~m}$ fall, are analysed.
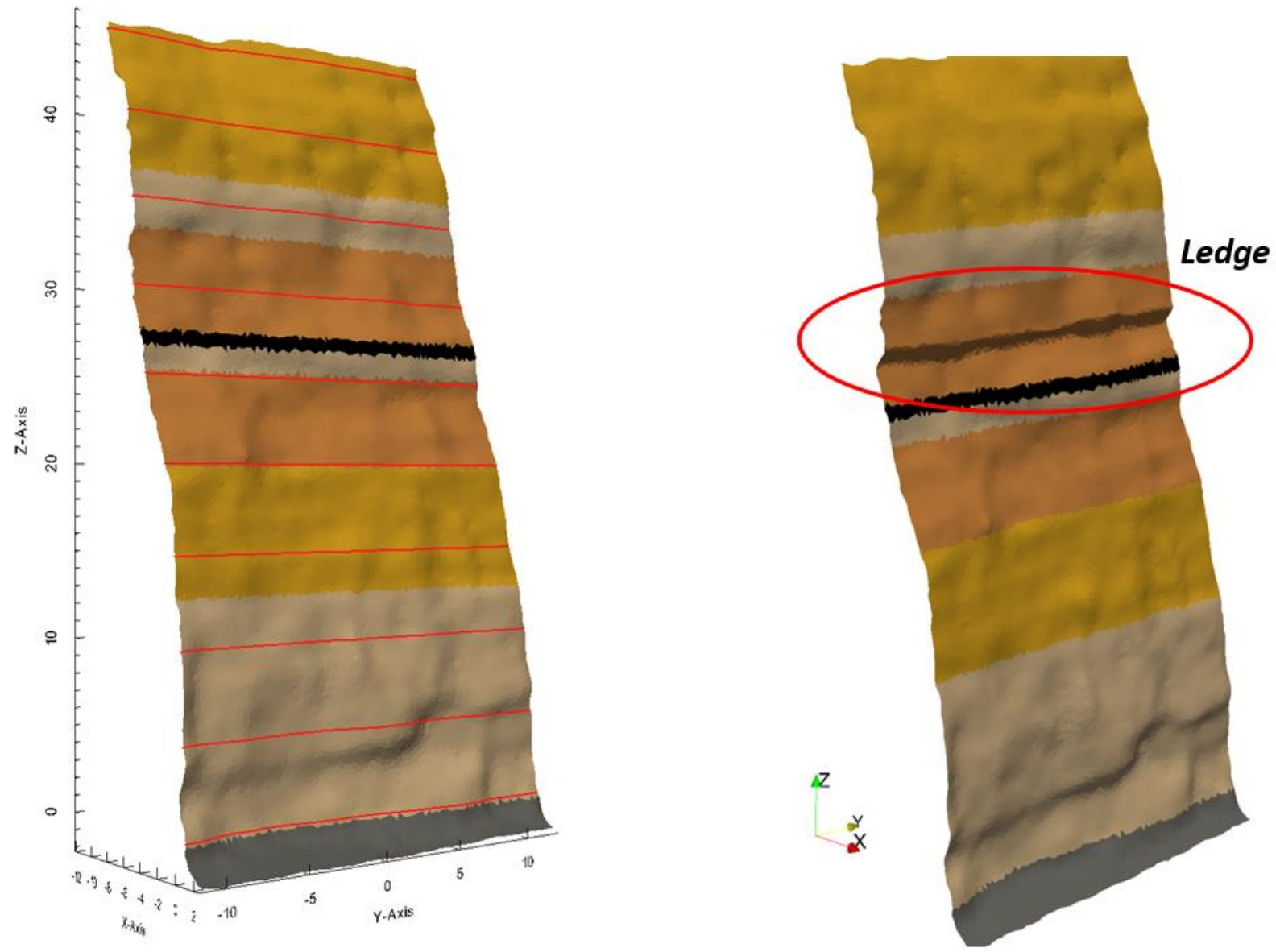

Figure 11 Standard highwall representation for rockfall trajectory study: (left) basic representation without ledge showing the dimensions with red lines every $5 \mathrm{~m}$; and, (right) example for an artificial modified geometry with ledge

Bottom impact energy is presented as a function of block mass in Figure 12. Results suggest block mass is the primary controlling factor and that block shape and slope morphology only have a secondary influence. The efficiency of the drapery, expressed as an energy dissipated ratio $\left(1-E_{k i n} / E_{p o t}\right)$, decreases with block mass. Bottom impact energy can be estimated from an average trend line defined as:

$$
E=C_{k} \times m^{\alpha}
$$

where: $C_{k}=50$ and $\alpha=1.2$.

It should be noted that the energy calculated with the above equation is limited to the available potential energy defined by $\mathrm{m} \times \mathrm{g} \times 40$. 


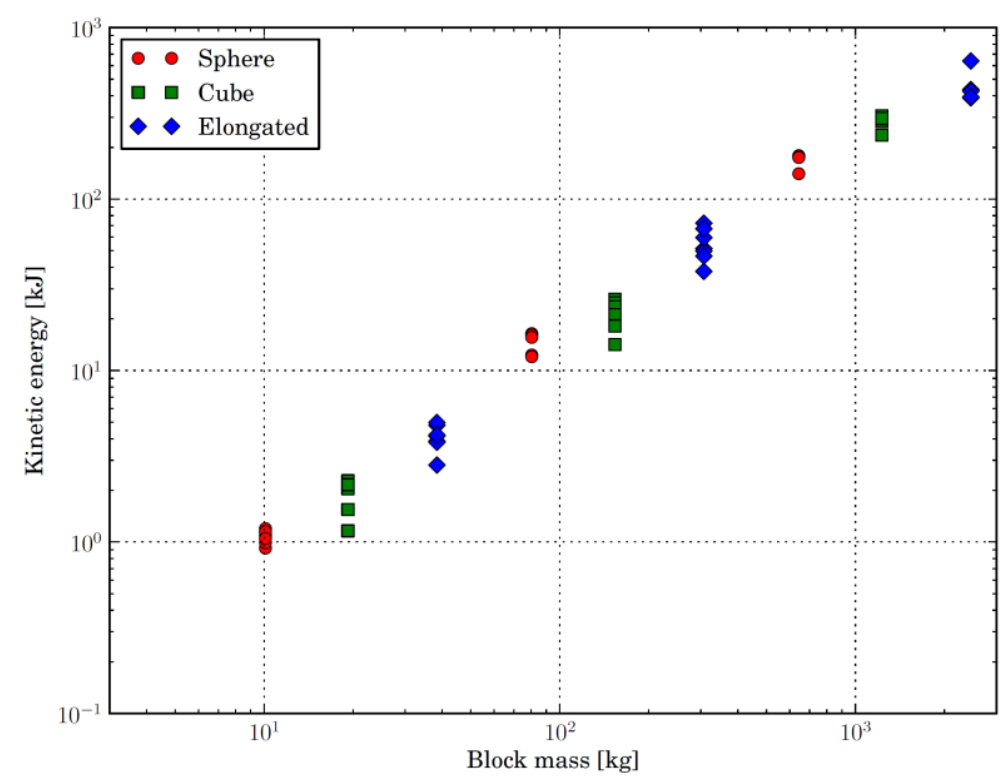

Figure 12 Bottom impact kinetic energy as a function of mass for all combinations of block shapes, sizes and slope morphologies

The bottom impact location is plotted as a function of block mass (Figure 13).

$$
d_{\max }=C_{d} \times m^{\beta}
$$

where: $C_{d}=0.4$ and $B=0.4$.

Giacomini et al. (2012b) performed in situ rockfall experiments behind draperies using $44.5 \mathrm{~kg}$ concrete blocks. Equations (2) and (3) lead to expected impact energy of $5 \mathrm{~kJ}$ and impact location at approximately $2 \mathrm{~m}$ from the highwall. Results from the experiments suggest impacts are reduced to less than $4 \mathrm{~kJ}$ and location varies between 1.3 and $2.1 \mathrm{~m}$ horizontally from the highwall, confirming the suitability of the approach for preliminary estimates.

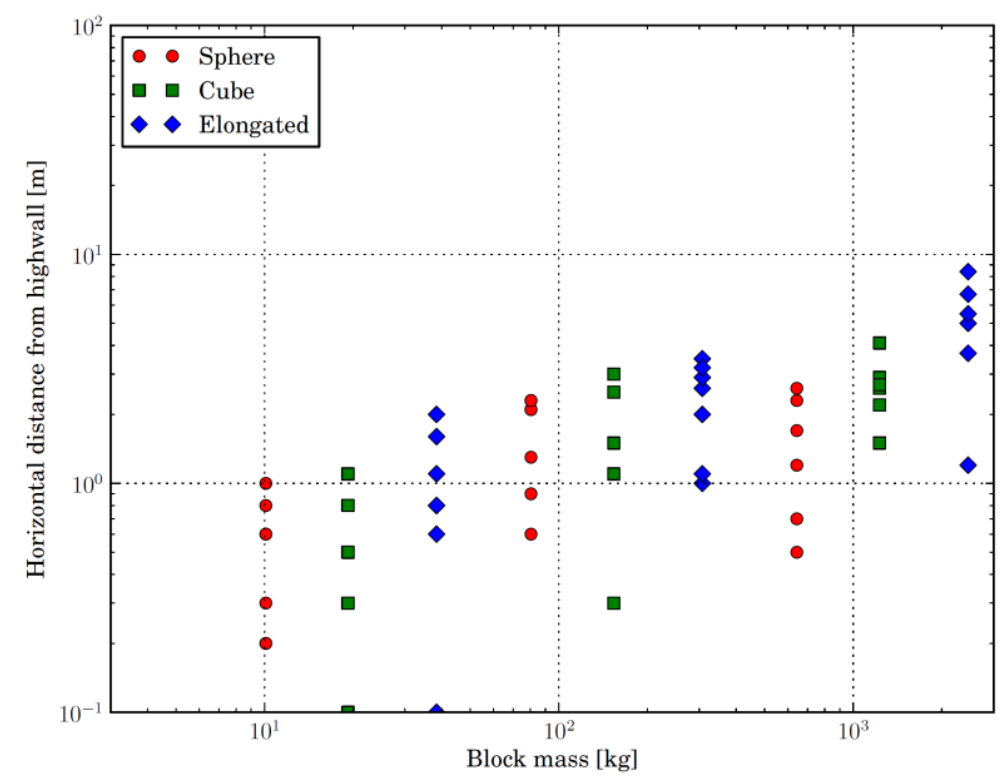

Figure 13 Bottom impact location as a function of mass for all combinations of block sizes, shapes and slope morphologies 


\section{Recommendations for portal design}

No general guidance currently exists regarding the design of underground entry portals. Rockfall scenarios considered for their design vary from mine to mine and usually arbitrary. The relationship derived in the previous section can be used to provide preliminary estimates of portal design criteria. For example, considering a design block size of $25 \mathrm{~kg}$, the drapery is expected to constrain block impacts to within $1.5 \mathrm{~m}$ of the highwall and impact energy is expected to exceed $2.4 \mathrm{~kJ}$. Therefore, any concrete portal structure constructed at the base of the highwall should be a minimum of $1.5 \mathrm{~m}$ long. A provision should be made to account for subsequent impacts along the portal to provide a safe access. In addition, the concrete structure should be able to sustain impacts exceeding $2.4 \mathrm{~kJ}$. This value differs significantly from the two typical design scenarios reported in Giacomini et al. (2012a) and discussed further below.

\subsection{Free fall scenario}

This scenario considers a cube with sides measuring $0.3 \mathrm{~m}$ and a density of $2,400 \mathrm{~kg} / \mathrm{m}^{3}$ falling from a height of $75 \mathrm{~m}$. No protection system is considered, which means the impact velocity of the block on top of the portal is as follows:

$$
\mathrm{v}=\sqrt{2 \mathrm{gH}}=\sqrt{2 \times 9.81 \times 75}=38.4 \mathrm{~m} / \mathrm{s}
$$

Considering a mass of $65 \mathrm{~kg}$ the kinetic energy can be calculated as:

$$
E_{C}=\frac{1}{2} m v^{2}=\frac{1}{2} \times 0.065 \times 38.4^{2}=47.9 \mathrm{~kJ}
$$

Therefore, the kinetic energy used in the design is $47.9 \mathrm{~kJ}$.

Now, the same scenario, but with a rockfall netting installed, is considered. The information collected during the experimental tests presented in Section 4 can be used to estimate the energy. The blocks used in the experiment were not cubes and they had a mass of $45 \mathrm{~kg}$. However, the dimensions are similar. During the experimental tests, the rockfall netting dissipated about $22 \%$ of its initial mechanical energy and the average energy dissipation upon impacts of $43 \%$ of its initial mechanical energy, was observed. Considering $75 \mathrm{~m}$ of highwall, the initial mechanical energy consists of potential energy, which can be calculated as:

$$
E_{p o t}=m g H=0.065 \times 9.81 \times 75=47.8 \mathrm{~kJ}
$$

The final kinetic energy on top of a portal, with consideration of a rockfall netting, can now be estimated as $35 \%$ of the initial mechanical energy: $22 \%$, or $10.5 \mathrm{~kJ}$, was dissipated by the netting, and $43 \%$, or $20.5 \mathrm{~kJ}$, by impacts on the highwall. This gives a final kinetic energy, on top of the portal, of $16.7 \mathrm{~kJ}$, which corresponds to about one third of the kinetic energy calculated without rockfall netting. As no relationship between the size of the block and the percentage of energy absorbed by impact and the netting has been established, this estimation should not be extended to any other scenario than the one explicitly modelled.

\section{$5.2 \quad$ Scenario with $500 \mathrm{~kg}$ block}

This scenario considers a block with a mass of $500 \mathrm{~kg}$ falling in-between the highwall and the rockfall netting. The mass is defined as the lower limit for rocks, which can be effectively pinned with rockbolts. The general assumption for such a scenario is that the impact velocity is reduced by the frictional resistance of the mesh installed on the highwall. An impact velocity of $2 \mathrm{~m} / \mathrm{s}$ is assumed, which corresponds to a kinetic energy of $1 \mathrm{~kJ}$. From the relationships derived in Section 4.2, a $500 \mathrm{~kg}$ block falling behind a drapery is expected to have a kinetic energy of $86.6 \mathrm{~kJ}$, corresponding to an impact velocity exceeding $18 \mathrm{~m} / \mathrm{s}$. It can clearly be seen that the frictional resistance of the mesh is overestimated and the kinetic energy considered in the design is far too low. In some reports values other than $2 \mathrm{~m} / \mathrm{s}$ can be found such as $5 \mathrm{~m} / \mathrm{s}$. The kinetic energy corresponds to $6.3 \mathrm{~kJ}$ which is still more than 10 times smaller than the expected impact energy. 


\section{Conclusion}

This paper presents a series of trajectory simulations that have been performed to derive qualitative relationships to estimate impact energies and locations at the base of a highwall for preliminary design purposes. Two different approaches are proposed to account for the presence or absence of a drapery on the slope. Results of these simulations suggest that rockfall scenarios currently used in the industry to design underground portals may not be adequate and that, for example, the friction resistance offered by unsecured draperies is largely overestimated. The portals, therefore, rely heavily on the presence of a granular dissipative layer (such as muck pile material) on top of them.

The relationships and general guidance described in this paper should only be used for preliminary design purposes and are proposed as a means to quickly identify the need for additional analysis and the most appropriate mitigation strategy. The approaches described, herein, can be adapted at the detailed design stage to provide site specific design criteria and to perform a quantitative hazard assessment.

\section{References}

Abbruzzese, JM, Sauthier, C \& Labiouse, V 2009, 'Considerations on Swiss methodologies for rock fall hazard mapping based on trajectory modelling', Natural Hazards and Earth System Science, vol. 9, pp. 1095-1109.

Alejano, LR, Stockhausen, HW, Alonso, E, Bastantea, FG \& Ramírez Oyangurenc, P 2008, 'ROFRAQ: A statistics-based empirical method for assessing accident risk from rockfalls in quarries', International Journal of Rock Mechanics and Mining Sciences, vol. 45, pp. 1252-1272.

Bertolo, P, Oggeri, C \& Peila, D 2009, 'Full-scale testing of draped nets for rockfall protection', Canadian Geotechnical Journal, vol. 46, pp. 306-317.

Ferrari, F, Thoeni, K, Giacomini, A \& Lambert, C 2016, 'A rapid approach to estimate the rockfall energies and distances at the base of rock cliffs', Georisk, in press, DOI: 10.1080/17499518.2016.1139729.

Giacomini, A, Lambert, C \& Thoeni, K 2012a, Improved management of the rock fall hazard at the base of the highwalls, Australian Coal Association Research Program, Project C19026.

Giacomini, A, Thoeni, K, Lambert, C, Booth, S \& Sloan, SW 2012b, 'Experimental study on rockfall drapery systems for open pit highwalls', International Journal of Rock Mechanics and Mining Sciences, vol. 56, pp. 171-181.

Lambert, C, Thoeni, K, Giacomini, A, Casagrande, D \& Sloan, S 2012, 'Rockfall hazard analysis from discrete fracture network modelling with finite persistence discontinuities', Rock Mechanics and Rock Engineering, vol. 45, pp. 871-884.

Muhunthan, B \& Radhakrishnan, H 2007, Finite element analysis of hybrid barrier for Rockfall slope protection - final report, technical report, Washington State University.

Thoeni, K, Lambert, C, Giacomini, A \& Sloan, SW 2013, 'Discrete modelling of hexagonal wire meshes with a stochastically distorted contact model', Computers and Geotechnics, vol. 49, pp. 158-169.

Thoeni, K, Giacomini, A, Lambert, C, Sloan, SW \& Carter, JP 2014, 'A 3D discrete element modelling approach for rockfall analysis with drapery systems', International Journal of Rock Mechanics and Mining Sciences, vol. 68, pp. 107-119.

Trad, A, Limam, A, Bertrand, D \& Robit, P 2011, 'Multi-scale analysis of an innovative flexible rockfall barrier', in S Lambert \& F Nicot (eds), Rockfall Engineering, ISTE, Wiley Publisher, pp. 303-342.

Volkwein, A 2005, 'Numerical Simulation of flexible rockfall protection systems', ASCE International Conference on Computing in Civil Engineering, Cancun.

Volkwein, A, Schellenberg, K, Labiouse, V, Agliardi, F, Berger, F, Bourrier, F, Dorren, LKA, Gerber, W \& Jaboyedoff, M 2011, 'Rockfall characterization and structural protection - a review', Natural Hazards Earth System Sciences, vol. 11, pp. 2617-2651. 